\title{
RADIOCARBON DATING OF KOHITSUGIRE (PAPER FRAGMENTS) ATTRIBUTED TO JAPANESE CALLIGRAPHISTS IN THE HEIAN-KAMAKURA PERIOD
}

\begin{abstract}
Hirotaka Oda ${ }^{1,2} \cdot$ Kazuomi Ikeda $^{3} \cdot$ Takashi Masuda $^{4}$ Toshio Nakamura ${ }^{1}$
ABSTRACT. A kohitsugire is a paper fragment from an old manuscript written mainly in the Heian and Kamakura periods. Although they contain significant information for historical, literary, and paleographical study, because of their antique handwriting and description of historical incidents, there are many copies and counterfeits written several centuries later. In this study, radiocarbon ages of kohitsugire were measured by accelerator mass spectrometry (AMS). On the kohitsugire attributed to the famous calligraphists in the Kamakura period (Fujiwara no Sadaie and Prince Munetaka), ${ }^{14} \mathrm{C}$ dating indicated that they were not genuine and should be excluded from the materials for study of the calligraphists. Calibrated ${ }^{14} \mathrm{C}$ ages of the kohitsugire attributed to Fujiwara no Yukinari indicated the middle Heian period. This calligraphy was written on Tobikumogami paper, which has a billowing cloud pattern decorated with indigo-blue-dyed fiber. Although it was commonly accepted that the Tobikumogami is peculiar to the middle 11 th to early 12 th century, the results from ${ }^{14} \mathrm{C}$ dating also suggested that the origin of the Tobikumogami would date back to the last of the 10th or the early 11th century, when Fujiwara no Yukinari flourished as a calligraphist. Calibrated ${ }^{14} \mathrm{C}$ ages of the kohitsugire attributed to Nijo Tameuji and Reizei Tamesuke showed that they are fragments of old manuscripts describing lost tales and were written in the 13th-14th century. Consequently, ${ }^{14} \mathrm{C}$ dating clarified the existence of ancient tales which had been unknown and indicated their worth as a material for the study of classical Japanese literature.
\end{abstract}

\section{INTRODUCTION}

In Japanese history, the Heian period usually indicates a span from AD 794, when Emperor Kanmu relocated the capital in Heiankyo (present-day Kyoto Prefecture), to AD 1192, when the Kamakura Shogunate was established as the first military government by Minamoto no Yoritomo. The Kamakura period corresponds to the duration of the Kamakura Shogunate (1192-1333).

The literary history of the Heian and Kamakura periods is surveyed below. The composition of Chinese poetry was considered as an obligatory accomplishment for nobles; accordingly, the major genre of literature were anthologies of Chinese poetry during the first $100 \mathrm{yr}$ of the Heian period. The development of the Japanese kana syllabary in the early 10th century, however, brought about a burst of native literature because it was now possible to write calligraphy without depending on Chinese characters. Nobles occasionally held the competitions of waka (Japanese poetry) and poetry anthologies of waka were compiled. The kana syllabary also caused the creation of a prose literature, including the monogatari (tale), the nikki (diary), and the zuihitsu (essay). The most famous of these literatures is perhaps Genji monogatari (The Tale of Genji), which recounts the life of a nobleman named Hikarugenji in the Heian period court. During the last Heian and the Kamakura periods, this field produced various literary forms: the gunkimono (war tale), the rekisi monogatari (historical narrative), the kiko (itinerary), and the setsuwa shu (anthology of short narratives, legends, and historical incidents). Heike monogatari (The Tale of the Heike), which is well known and recited to a biwa accompaniment, followed the establishment of the Kamakura shogunate; the tale centers on the rise and fall of the Taira warrior and gives a description of the Taira-Minamoto War.

Classical literature also provides significant information for historians because of the description of historical incidents, and for the study of paleography because of the antique calligraphy. The study

\footnotetext{
${ }^{1}$ Center for Chronological Research, Nagoya University, Chikusa, Nagoya 464-8602, Japan.

${ }^{2}$ Corresponding author. Email: oda@nendai.nagoya-u.ac.jp.

${ }^{3}$ Chuo University, Higashinakano, Hachioji, Tokyo 192-0351, Japan.

${ }^{4}$ Aichi Bunkyo University, Komaki, Aichi 485-0802, Japan.
} 
of classical literature, history, and paleography generally requires the source book or the old manuscripts to be copied with few mistakes or alterations. However, complete manuscripts written during the Heian and Kamakura period are quite rare. One of the main reasons can be ascribed to the Onin War (1467-1477), which was the nationwide war triggered by a conflict over the successor of shogun. The greater part of Kyoto was burned down and a large quantity of ancient documents and treasures kept in temples, shrines, and nobles' mansions were reduced to ashes in the war. In addition, the development of the tea ceremony indirectly accelerated the decrease of the old manuscripts. Because the tea ceremony was popular among military lords and wealthy merchants in the 16th century, in order to appreciate their elegant and antique calligraphy in the teahouses, the old manuscripts had been cut page by page and mounted on hanging scrolls for decoration.

Although the old manuscripts are rarely discovered as complete books, the kohitsugire paper fragments hold potentially significant information for historical study. There are, however, many copies and counterfeits written several centuries later among the kohitsugire fragments attributed to the famous calligraphists. While the written age or the author of the ancient manuscript can be generally presumed by the paleographical views, it is generally difficult to ascertain whether kohitsugire with only a few calligraphic lines are genuine or not.

We have been working on radiocarbon dating focused on ancient Japanese documents and sutras of known age (Oda et al. 2000, 2003). These previous studies indicated that calibrated ${ }^{14} \mathrm{C}$ ages of Japanese paper are in good agreement with assumed corresponding historical ages of the documents or sutras. In this paper, we further examine the suitability of this material for historical study, and have measured the ${ }^{14} \mathrm{C}$ ages of the kohitsugire fragments traditionally attributed to the famous Japanese calligraphists in the Heian-Kamakura period.

\section{SAMPLES}

In this study, ${ }^{14} \mathrm{C}$ ages of 9 kohitsugire samples were measured. They include 3 samples (nr I-III, Table 1) of which the written ages were determined by evidence based on historical, paleographical, and bibliographical views. Sample nr I is a fragment of the Chusonji konshi kinginkosho issaikyo sutra. This sutra was written on indigo-blue-dyed paper with gold and silver Indian inks in alternate lines. It is assumed to have been written in the early 12 th century (1117-1125) at the request of Fujiwara no Kiyohira (1056-1128) for the completion ritual of the Golden Hall of the Chusonji temple (1126) in Hiraizumi (present-day Iwate Prefecture). Sample nr II is an ancient letter with the compliments of the New Year. It was attached to the back of a sheet of the Inmyo mondo sho sutra. Several letters from the same sender were pasted together and the sutra was written on the back side of the recycled paper. Such sutras were commonly written as condolences for death of the original sender. The sutra was written in 1315; accordingly, the date when the letter was originally sent should be a few years or decades before. Sample nr III is a paper fragment of the last page of an ancient book. Since this part corresponds to a colophon, it has a writer's signature, "Nakanoin Nobutane", a signature stamp, and an account that the book was written in 1501 at the request of a person by the name of Kijumaru. Based on the handwriting and the ancient records on Nakanoin Nobutane, it is fairly certain that the kohitsugire is a genuine calligraphy of Nakanoin Nobutane.

Table 1 The kohitsugire samples of known age.

\begin{tabular}{lll}
\hline $\mathrm{Nr}$ & Sample name & Written age (AD) \\
\hline I & Chusonji konshi kinginkosho issaikyo sutra & $1117-1125$ \\
II & A letter on the back on Inmyo mondosho sutra & 1315 \\
III & The last page of a book by Nakanoin Nobutane & 1501 \\
\hline
\end{tabular}


The written ages of the other 6 samples (nr 1-6, Table 2) have no reliable evidence from paleographical studies and leave room for further examination, especially by ${ }^{14} \mathrm{C}$ dating. The estimated paleographical ages are listed in Table 2. Some kohitsugire fragments had small labels attached (called kiwamefuda) upon which are the calligraphists' names. The calligraphists noted on the kiwamefuda are also indicated in Table 2. Most of them, however, have no evidence based on paleographical studies.

Table 2 The kohitsugire samples of unknown age.

\begin{tabular}{llll}
\hline $\mathrm{Nr}$ & Sample name & Calligraphist on the Kiwamefuda & Estimated paleographical age \\
\hline 1 & Itsumei honcho kaku gire & Fujiwara no Yukinari (971-1027) & $\begin{array}{l}\text { 971-1027 or middle 11th-early } \\
\text { 12th century }\end{array}$ \\
2 & Ise monogatari & Fujiwara no Sadaie $(1162-1241)$ & 14th century \\
3 & Kokin wakasyu anthology & Fujiwara no Sadaie $(1162-1241)$ & - \\
4 & The anthology of Fujiwara no & Prince Munetaka (1242-1274) & The latter half of the 11th century \\
& Sanekata's poetry & & \\
5 & A lost tale by Nijo Tameuji & Nijo Tameuji (1222-1286) & - \\
6 & A lost tale by Reizei Tamesuke & Reizei Tamesuke (1260-1328) & - \\
\hline
\end{tabular}

\section{METHODS}

The kohitsugire fragment is commonly mounted on another paper sheet. In addition, some of them have double or triple sheets. Paper samples (20-130 mg) were cut from the margins of the calligraphies and were soaked with distilled water to peel the surface fragments from the mounts. All the sample fragments were first washed with distilled water in an ultrasonic cleaner and then treated with $1.2 \mathrm{~N} \mathrm{HCl}$ and $1.2 \mathrm{~N} \mathrm{NaOH}$ solutions on a hot plate (each step was repeated 5 times for $2-3 \mathrm{hr}$ at $60-70{ }^{\circ} \mathrm{C}$ ). Next, alpha-cellulose was prepared from samples $\mathrm{nr}$ II, III, 1, 3-5: they were bleached 4 times with $0.07 \mathrm{M} \mathrm{NaClO}_{2}$ solution under acidic conditions adjusted with $\mathrm{HCl}\left(70-80{ }^{\circ} \mathrm{C}, 1 \mathrm{hr}\right)$, treated with $17.5 \% \mathrm{NaOH}$ solution for $30 \mathrm{~min}$ at room temperature, and finally rinsed with $1.2 \mathrm{~N} \mathrm{HCl}$ and distilled water. The surface sheets of 3 kohitsugire (nr I, 2, 6) are small fragments; therefore, they were treated again with $1.2 \mathrm{~N} \mathrm{HCl}\left(3\right.$ times, $\left.3-4 \mathrm{hr}, 60-70^{\circ} \mathrm{C}\right)$ and rinsed with distilled water instead of alpha-cellulose extraction in a lower yield. After drying in a vacuum desiccator, each sample was sealed in a Vycor glass tube with $\mathrm{CuO}$ and converted to $\mathrm{CO}_{2}$ at $850{ }^{\circ} \mathrm{C}$ for $2 \mathrm{hr}$. The $\mathrm{CO}_{2}$ gas was purified on an evacuated glass line with successive traps cooled with chilled ethyl alcohol, solid n-pentane, and liquid nitrogen. The purified $\mathrm{CO}_{2}$ gas was reduced with hydrogen to graphite in the presence of an iron catalyst at $650^{\circ} \mathrm{C}$ for $6 \mathrm{hr}$.

The AMS measurements were run on a Tandetron accelerator mass spectrometer manufactured by HVEE (High Voltage Engineering Europa) at the Center for Chronological Research, Nagoya University, Japan. NBS oxalic acid (SRM-4990) was used as the standard material. Isotopic fractionation was corrected with ${ }^{13} \mathrm{C} /{ }^{12} \mathrm{C}$ ratios measured on the Tandetron spectrometer during the analysis. Each sample was measured 3 or 6 times.

\section{RESULTS}

Tables 3 and 4 show the averaged ${ }^{14} \mathrm{C}$ ages of the samples with $1 \sigma$ and $2 \sigma$ errors. The ${ }^{14} \mathrm{C}$ ages were calibrated to calendar yr using data from INTCAL98 (Stuiver et al. 1998). In the columns of calibrated ${ }^{14} \mathrm{C}$ age, the values inside parentheses are the calibrated yr of the mean ${ }^{14} \mathrm{C}$ age and the values outside indicate the error ranges. 
Table 3 Results of ${ }^{14} \mathrm{C}$ dating on the kohitsugire samples of known age.

\begin{tabular}{|c|c|c|c|}
\hline Sample nr & Lab nr (NUTA2-) & ${ }^{14} \mathrm{C}$ age (BP) & Calibrated ${ }^{14} \mathrm{C}$ age (cal AD) \\
\hline \multirow[t]{2}{*}{ I } & \multirow[t]{2}{*}{5209,5231} & $935 \pm 14(1 \sigma)$ & $\begin{array}{l}\text { 1036(1041)1065, } \\
\text { 1084(1094,1117)1123, } \\
1137(1141) 1144, \\
1147(1153) 1157\end{array}$ \\
\hline & & $935 \pm 28(2 \sigma)$ & $1028(1041,1094,1117,1141,1153) 1160$ \\
\hline \multirow[t]{2}{*}{ II } & \multirow[t]{2}{*}{383} & $656 \pm 22(1 \sigma)$ & $\begin{array}{l}1295(1300) 1304 \\
1367(1374,1376) 1384\end{array}$ \\
\hline & & $656 \pm 45(2 \sigma)$ & $\begin{array}{l}\text { 1288(1300)1326, } \\
1348(1374,1376) 1391\end{array}$ \\
\hline \multirow[t]{2}{*}{ III } & \multirow[t]{2}{*}{385} & $348 \pm 18(1 \sigma)$ & $\begin{array}{l}\text { 1487(1516)1523, } \\
1567(1598,1617) 1627\end{array}$ \\
\hline & & $348 \pm 37(2 \sigma)$ & $\begin{array}{l}\text { 1477(1516)1531, } \\
1543(1598,1617) 1635\end{array}$ \\
\hline
\end{tabular}

Table 4 Results of ${ }^{14} \mathrm{C}$ dating on the kohitsugire samples of unknown age.

\begin{tabular}{|c|c|c|c|}
\hline Sample nr & Lab nr (NUTA2-) & ${ }^{14} \mathrm{C}$ age (BP) & Calibrated ${ }^{14} \mathrm{C}$ age (cal AD) \\
\hline \multirow[t]{2}{*}{1} & \multirow[t]{2}{*}{2042} & $1104 \pm 20(1 \sigma)$ & $\begin{array}{l}897(903,916) 922, \\
943(964,972,975) 982\end{array}$ \\
\hline & & $1104 \pm 41(2 \sigma)$ & $891(903,916,964,972,975) 995$ \\
\hline 2 & 5212,5233 & $\begin{array}{l}685 \pm 14(1 \sigma) \\
685 \pm 28(2 \sigma)\end{array}$ & $\begin{array}{l}1289(1295) 1298 \\
1284(1295) 1301 \\
1371() 1379\end{array}$ \\
\hline 3 & 380 & $\begin{array}{l}240 \pm 23(1 \sigma) \\
240 \pm 46(2 \sigma)\end{array}$ & $\begin{array}{l}1647(1656) 1663 \\
1640(1656) 1670 \\
1780() 1797\end{array}$ \\
\hline \multirow[t]{2}{*}{4} & \multirow[t]{2}{*}{379} & $202 \pm 20(1 \sigma)$ & $\begin{array}{l}\text { 1661(1667)1673, } \\
1777(1782,1795) 1800, \\
1942() 1946\end{array}$ \\
\hline & & $202 \pm 41(2 \sigma)$ & $\begin{array}{l}\text { 1654(1667)1679, } \\
1740() 1753, \\
1756(1782,1795) 1804, \\
1935() 1947\end{array}$ \\
\hline 5 & 382 & $\begin{array}{l}766 \pm 23(1 \sigma) \\
766+45(2 \sigma)\end{array}$ & $\begin{array}{l}1258(1275) 1280 \\
1221(1275) 1286\end{array}$ \\
\hline \multirow[t]{2}{*}{6} & \multirow[t]{2}{*}{5214,5234} & $670 \pm 14(1 \sigma)$ & $\begin{array}{l}\text { 1294(1297)1300, } \\
1372(01378\end{array}$ \\
\hline & & $670 \pm 28(2 \sigma)$ & $\begin{array}{l}\text { 1288(1297)1304, } \\
1367() 1384\end{array}$ \\
\hline
\end{tabular}

\section{DISCUSSION}

\section{Kohitsugire Samples of Known Age}

As shown in Table 3, the calibrated ${ }^{14} \mathrm{C}$ ages of samples $\mathrm{nr}$ I-III include the presumed paleographical ages. Similar corroboration of historical ages with ${ }^{14} \mathrm{C}$ dates were also found in the previous studies on the ${ }^{14} \mathrm{C}$ dating of ancient Japanese paper samples of known age (Oda et al. 2000, 2003). The results from these known-age samples indicate that the Japanese handmade paper these documents are written on is a suitable material for ${ }^{14} \mathrm{C}$ dating. There are several reasons for this. Japanese 
paper sheets were made mainly from branches of the following shrubs: Kozo (Broussonetia kazinoki $\times$ Broussonetia papyrifera), Ganpi (Diplomorpha sikokiana), and Mitsumata (Edgeworthia chrysantha). Fresh branches less than a few years old were also selected for paper manufacture since old branches yield paper of poor quality. Long preservation of Japanese handmade paper reduces the absorbency of the Indian ink and thin ink used to write on the old paper. Therefore, it is fairly certain that a new paper sheet was used for kohitsugire writing in which particular attention is paid to the deep-black tone of ink. In addition, if an old paper sheet was used for calligraphy, it can be paleographically distinguished because of its watery shade of ink.

We have also considered the tints given to the paper sheets themselves. Although the blue-dyed sample (nr I) was not completely bleached with acid-alkali-acid treatment and required further chemical treatment as described in the "Methods" section, the paper was tinted during production with indigo, which is a yearly plant and, thus, not a factor of contamination for our dating.

\section{Itsumei Honcho Kaku Gire}

Itsumei honcho kaku gire (nr 1) is a tale traditionally attributed to Fujiwara no Yukinari (familiarly called Kouzei, 971-1027), who is one of the most famous calligraphists in the middle Heian period. The handwriting of this kohitsugire is identical with that of Hakushishikan written by Kouzei in 1018; consequently, it was regarded as his genuine calligraphy. However, there remained a question. This calligraphy was written on the paper decorated with indigo-blue-dyed fiber, as if clouds are billowing in the sky. Such paper is called Tobikumogami. In the historical study on Japanese paper production, it is suggested by the extant Tobikumogami with known age that the Tobikumogami paper is peculiar to the middle 11th to early 12 th century (Yotsutsuji 2001). There was, thus, a question as to the difference between the timing of Kouzei's writings and the beginning of Tobikumogami paper production.

Our results show that the calibrated ${ }^{14} \mathrm{C}$ age of Itsumei honcho kaku gire indicates that it was written in the 10th century (891-995 cal AD, $2 \sigma$ ). It is suggested that all the extant Tobikumogami of known age postdate Itsumei honcho kaku gire. The cloud patterns in the Tobikumogami paper gradually varied: the old examples in the middle 11th century have relatively large clouds; the size became smaller in the late 11th century; and it changed into mere external decoration in the early 12th century (Yotsutsuji 2001). Itsumei honcho kaku gire has large and excellent cloud patterns. It is, therefore, fairly certain that Itsumei honcho kaku gire is the oldest example among the extant Tobikumogami. Although it had been commonly accepted that Tobikumogami paper was produced during quite a short period (middle 11th-early 12 th century), we propose, from our ${ }^{14} \mathrm{C}$ analysis and paleographical views, that the origin ascends back to the late 10th or early 11th century, when Kouzei flourished as a calligraphist. As to ascertaining whether the calligraphist was indeed Kouzei, we cannot make an unequivocal statement; there remains a possibility of other calligraphists in the middle Heian period, especially Prince Kaneakira (914-987) whose calligraphy is similar to that of Kouzei. However, based on the result of ${ }^{14} \mathrm{C}$ dating and the paleographical comparison with the handwriting of Hakushishikan (his genuine calligraphy), it seems reasonable that Itsumei honcho kaku gire was written by Kouzei.

\section{Kohitsugire Traditionally Attributed to the Famous Calligraphists}

Among the kohitsugire fragments, there are many copies and counterfeits written several centuries later by the following historical circumstances. The kohitsugire fragments of the ancient calligraphists in the Heian-Kamakura period had been used as models of calligraphy because of their antique, rare, and elegant handwriting. Moreover, the development of the tea ceremony in the 16th 
century increased the value of the kohitsugire as hanging scrolls. In the Edo period (17th-middle 19th century), collectors of kohitsugire appeared and compiled the albums of kohitsugire (called kohitsutekagami). These albums were treasured among upper-class samurai and court nobles. The kohitsutekagami has a definite order of calligraphists; therefore, many copies or counterfeits were required for incomplete kohitsutekagami albums. As a result, genuine calligraphies from kohitsutekagmi authors are, in fact, quite rare.

Fujiwara no Sadaie (1162-1241) is the greatest calligraphist of the Kamakura period; he is familiarly called Teika. The kohitsugire fragments of samples $\mathrm{nr} 2$ and 3 are traditionally attributed to him. Sample $\mathrm{nr} 2$ is a part of a scroll composed of 9 kohitsugire sheets. The subject of the scroll is a combination of a part of a waka poem recorded in the Shin kokin wakashu (the 8th imperial anthology, the original was compiled in 1205; Teika was an editor of the anthology); sentences with classical Chinese from Kinpisho written during 1219-1222 (including some words of the public posts in the Korean government from the 10th century downward: Koryo [918-1392] and Yi [1392-1910] dynasties); and the text of Ise monogatari ("The Tale of Ise", the original of which was written in the first half of the 10th century). If this kohitsugire are genuinely by Teika, it should be an essential reference not only for the study of calligraphy but for classic literature, especially because of the waka poem from Shin kokin wakashu and the description of the ancient tale, Ise monogatari. The waka and the text of the monogatri, however, appear to be written later in the margin of Chinese sentences of Kinpisho and the unidentified document. The calibrated ${ }^{14} \mathrm{C}$ age of sample $\mathrm{nr} 2$ indicates the late 13th or late 14th century (1284-1301, 1371-1379 cal AD, 2 \%), and it is reasonable to suppose that the kohitsugire is not a genuine calligraphy of Teika.

Sample $\mathrm{nr} 3$ is also attributed to Teika. This fragment is part of a selection of amorous poems from the Kokin Wakashu (the first imperial anthology; the original was compiled in 905). The thin handwriting, an individual style of Teika's writing in his youth, suggests that the anthology was written in about 1200. In addition, another kohitsugire fragment of amorous poems written in the identical handwriting of sample $\mathrm{nr} 3$ had been already authenticated as genuine calligraphy of Teika. However, these 2 fragments of amorous poems have a few kana characters which seem to be different from those of other genuine kohitsugire of Teika. Our ${ }^{14} \mathrm{C}$ results for sample $\mathrm{nr} 3$ indicated that this kohitsugire was written in the middle 17 th or the late 18 th century and, thus, not attributable to Teika.

Sample nr 4 is part of the anthology of Fujiwara no Sanekata's poetry. The original of the Sanekata anthology was edited in the 10th century (the middle Heian period). According to the Kiwamefuda label, it was written in the middle Kamakura period by Prince Munetaka (1242-1274). The Kiwamefuda label usually has no valid evidence based on paleographical studies. Actually, this kohitsugire is written in a second Koyagire style which is peculiar to the latter half of the 11th century. However, the handwriting appears to be less adept; therefore, the written age was not determined by the paleographical information. The calibrated ${ }^{14} \mathrm{C}$ age of the kohitsugire indicated a production period from the middle 17th century downward and that the paper sheet was manufactured in the Edo period; thus, the handwriting with this second Koyagire style was a counterfeit. Kohitsugire fragments nr 3 and 4 written in the Edo period would be for a hanging scroll or a kohitsutekagami album. They are not genuine calligraphies of Fujiwara no Teika and Prince Munetaka.

\section{The Lost Monogatari}

Some ancient tales created in the Heian and Kamakura period are still known in the present day: Genji monogatari, Taketori monogatari, and Ise monogatari are famous examples. However, many other tales were lost by the subdivision of the old manuscripts. Among kohitsugire, there are some fragments with parts of a certain tale which do not match any extant ancient tales and seem to be the 
kohitsugire of heretofore unknown tales. If the date of production or the author of such Kohitsuire fragments were uncovered, it would be a significant material clue for reconstruction of the lost tale.

We chose 2 kohitsugire fragments of lost tales for AMS analysis. Because of their tone of ink, it is fairly certain that they were not written on long-preserved paper sheets. Kohitsugire nr 5 is attributed to Nijo Tameuji (1222-1286), and our analysis indicated that this fragment was written in the middle Kamakura (1221-1286 cal AD, $2 \sigma)$. This result corresponds to the period when Tameuji flourished as a calligraphist. Fragment nr 6 comes from a lost tale attributed to Reizei Tamesuke (1260-1328). The results on this kohitsugire (1288-1304, 1367-1384 cal AD, $2 \sigma$ ) also includes the time when Tamesuke flourished. Although the error range reached to the late 14th century, it is obvious that the kohitsugire was not a counterfeit made from the 16th century downward. Our analysis indicated that these 2 kohitsugire are not forgeries for hanging scrolls or kohitsutekagami albums. It also supports their worth for the study of classical literature as fragments from old manuscripts of lost tales. The collection of other kohitsugire fragments with identical handwriting and dating by paleographical views or ${ }^{14} \mathrm{C}$ method will, thus, assist the reconstruction of lost tales written in the Kamakura period.

\section{CONCLUSION}

${ }^{14} \mathrm{C}$ ages of kohitsugire fragments were measured by the AMS method. The results on the kohitsugire of known age supported that Japanese paper is suitable sample for ${ }^{14} \mathrm{C}$ dating because of the small discrepancy between the calibrated ${ }^{14} \mathrm{C}$ age and the historical age. The ${ }^{14} \mathrm{C}$ dating on samples of unknown age provided new information for the written age, the author, the history of paper manufacture, and also the estimation of the worth as a material for the study on classical literature, history, and paleography.

\section{ACKNOWLEDGEMENTS}

This research was supported in part by a Grant-in Aid for Young Scientists (B) (nr 14780091) from the Japan Society for the Promotion of Science.

\section{REFERENCES}

Oda H, Yoshizawa Y, Nakamura T, Fujita K. 2000. AMS radiocarbon dating of ancient Japanese sutras. $\mathrm{Nu}$ clear Instruments and Methods in Physics Research B 172:736-40.

Oda H, Masuda T, Niu E, Nakamura T. 2003. AMS radiocarbon dating of ancient Japanese documents of known age. Journal of Radioanalytical and Nuclear Chemistry 255(2):375-9.
Stuiver M, Reimer PJ, Bard E, Beck JW, Burr GS, Hughen KA, Kromer B, McCormac FG, van der Plicht J, Spurk M. 1998. INTCAL 98 radiocarbon age calibration, 24,000-0 cal BP. Radiocarbon 40(3):104183.

Yotsutsuji H. 2001. Glossary. Decorative Papers. Aichi, Japan: The Tokugawa Museum. p 220-9. In Japanese, with English abstract. 